\title{
त्री \\ On the status and role of instrumental images in contemporary science: some epistemological issues
}

Hermínio Martins

\begin{abstract}
电
ABSTRACT

The controversy over imageless thought versus picture thinking (especially via mechanical models), with the recent reconsideration of model-based reasoning in the physical sciences is briefly examined. The main focus of the article is on the role of instrumentally elicited images (scopic instruments, cameras, CCDs) in the sciences, especially in the physical sciences, with special reference to optics, experimental particle physics and observational astronomy, against the background of the civilization of digital images, though to some degree every scientific discipline is implicated. Imaging, today chiefly in the mode of electronic digital visual imaging, reaches into every phase of scientific inquiry, observational, experimental, simulational, even in mathematical research. The combination of algorithms and image-intensive science with the plethora of big data results in an epistemic pattern of "mathematical imagism". The epistemological issues regarding the image-intensiveness as of data-intensiveness of scientific research deserve further probing, in pursuance of the discussions of the ideal of mechanical objectivity in machine vision (an ever greater proportion of scientific visualization) versus trained judgment in the selection and assessment of scientific images: as for now tacitly we depend on conventions regarding what we called "warranted imageability".
\end{abstract}

KEYwords • Images. Digital images. Visualization in contemporary science.

Third paradigm of science. Fourth paradigm of science. Automation of science work.

Mathematical imagism. Warranted imageability.

I will not be concerned with the role of mental imagery ("pictures in our heads") in scientific cognition, and especially in scientific creativity, a topic which has attracted a lot of interest lately, not least in connexion with renewed interest in gedankenexperimente (cf. Miller, 1984), nor with the cognitive science approach to model-based reasoning in, for example, physics, which images may play an important part, as in the work of Maxwell (cf. Nersessian, 2008). My sole concern is with visual images elicited by instruments, and mostly with photographs, still or moving, in scientific research. The bulk of the literature deals with visual rather than auditory models, the relevance of which was pointed out long ago by the philosopher of physics, Milic Capek (1961), but 
has attracted little attention since in mainstream science studies. In this paper my examples will be drawn mostly from the physical sciences, and to some extent biology, mostly excluding the social and human sciences (and thus visual anthropology and visual sociology), and the environmental sciences, where imaging is so important today, and visual representation preeminent for nearly two centuries.

\section{Science and the “Givilization of images"}

The "cultural sensorium", the typical value hierarchy of the senses, of the West, has raised sight to the top, with hearing in the second place, the distance senses, at least since Aristotle eulogized vision at the beginning of his Metaphysics (cf. Jonas, 1966a). In recent times the hegemony of vision in the West, its prepotent "ocular-centric" bias, the "despotism of the eye" of Coleridge (cf. Engell \& Bate, 1983 [1817]), have been the target of critics of scientific rationality and technological civilization (cf. Jay, 1993a; 1993b). The West has built the glass civilization par excellence, surpassing all others in the widespread and multifunctional use of glass in mirrors, lenses, devices, windows, buildings (cf. Macfarlane \& Martin, 2003). In the West, for the first time, there took place an extraordinary diffusion of glass mirrors and glass windows, even in the humblest domestic settings, an obsession with light, centuries of advances in the glass industry, a unique development of urban glass architecture, a steady development of the arts and technologies of seeing. Specifically, the invention of innumerable "scopic" instruments of ever-increasing capabilities, originally in the context of early modern "natural magic" (cf. Hankins \& Silverman, 1995), before being incorporated in routine scientific practices, from the spread of "eyeglasses" in the Middle Ages to the powered automated super-telescopes of today has sustained a centuries-long and now accelerating growth of observational science. ${ }^{1}$ Science came to depend also, with the printing revolution and linear perspective, on prints, engravings and printed drawings for anatomy and natural history, in particular. The Encyclopédie of Diderot and D'Alembert contained a large number of plates depicting the state of all the major arts and crafts in Europe.

But it was photography which multiplied beyond measure the actual and potential image repertoire of scientific inquiry and truly launched the "civilization of images" (cf. Gusdorf, 1960) in which we dwell, more specifically a "civilization of proliferating image technologies", now above all the "civilization of digital images". In fact,

1 As late as the mid-twentieth century the famous biologist E. O. Wilson did much of his work on entomology with a magnifying glass. 
photography was deployed for scientific uses at its inception: the first astronomical photograph was taken in 1839 by Louis Daguerre himself. At any rate, this was the first such to be legitimated by a prominent scientist, François Arago, for whom it inaugurated an epoch of photography of great value for scientific knowledge (cf. Sicard, 1998). The regular use of photographic images in scientific investigation, or even for providing records of artifacts or other objects to complement verbal descriptions, emerged within a couple of decades or so, Marey, Muybridge and Galton being some of the key names in this connection. The extraordinary series of photographs by the French physiologist Duchenne de Boulogne of the activation of facial muscles published in his $\mathrm{Al}$ bum of pathological photographs (1862) inspired Darwin's treatment of facial expressions in The expression of the emotions in man and animals, ten years later (cf. Sicard, 1998). In the 1880s Ernst Mach developed a high-speed photographic apparatus to track the shock waves of bullets and shells in his pioneering research on supersonic motion. With the serendipitous discovery of X-rays photography in 1897 , and especially after that of $X$-rays diffraction, this kind of photography became very widely deployed for scientific and medical purposes. The $\mathrm{X}$-ray photographs taken by Rosalind Franklin in the process that led to the formulation of the double helix model of the structure of DNA in $195^{3}$ remain the greatest single achievement of the genre.

"Perceptual revolutions" have been defined as "radical changes to the way in which a viewer perceives almost any visible change" (Novitz, 1977, p. 124): "a number of pictorial styles have prompted viewers to look at depicted objects in terms of pictures of them" (p. 122-3). The diffusion of photography certainly brought about a perceptual revolution on a grander scale than any other in history till then, as the major promoter of the "civilization of images", for the photograph taught us to see the world photographically (cf. Ivins, 1953 , p. 94). ${ }^{2}$ It thereby made the world available in new ways for both aesthetic and scientific apperception.

Photography was at first imputed an eminent degree of veracity, of representative realism, of fidelity to the real (or at least to appearances), comparable only to the best-authenticated empirical scientific knowledge, or to veridical sense-perception. It became clear that this was not so, inasmuch as falsifications and distortions could arise, by design or not, and therefore, for scientific purposes, controls were needed as for other data-gathering and observation-recording pursuits, such as telescopic or

2 New modes of perception can also be induced through non-image technologies such as "panoramic perception", elicited by railway travel in the early nineteenth century: "the empirical reality that made the landscape seen from the train window appears to be 'another world' was the railroad itself" (Schivelbusch, 1979, p. 24). But even before the fashion for balloons starting in the eighteenth century had afforded a similar kind of panoramic perception with aerial rather than terrestrial views. "Panoramas" in the original sense of entertainment devices, popular until the 186os, familiarized many with an ersatz experience of this kind. 
microscopic investigations. Even in the late nineteenth century some astronomers still raised doubts about the scientific validity of astronomical photography, just as doubts had been raised much earlier about the epistemic warrant of the observations in Galileo's telescope, and similar doubts would be raised in the mid-twentieth century about the cognitive reliability of electronic microscope, and that of the radar telescope, as against the optical versions, at the time of their introduction. A notorious controversy over the issue took place between two outstanding Cambridge astrophysicists, Fred Hoyle and Martin Ryle, in the 1960s. No such heated controversy has taken place over the epistemic import of subsequent image technologies in exact science, at least not among scientists. A counter-strategy would be to automate or mechanize the whole process of the production of photographic images, in the search of what one might call absolute machine vision, untainted by human perceptual flaws, unconscious inferences (the "optical unconscious" of Benjamin), or human mishandling of any kind, according to what has been called "the ideal of mechanical objectivity". To be sure, it is supposed that the imaging technology does not causally affect the putative representandum so as to distort the fidelity of the representamen. Such alleged effects were the ground for the initial objections to the electronic microscope. The ideal of mechanical objectivity was most challenged in the philosophy of science by the physical chemist and thinker Michael Polanyi (1958).

Digital images - substantially different from analog photographs, hence the term "post-photographic" era (cf. Mitchell, 1992) - carry out this aim of algorithmicization through and through of the process of imaging, which has seemed technologically feasible, with very powerful robotized telescopes, or with space probes transmitting data at enormous distances from the Earth, for example. Machine vision flourishes as never before, in and out of science, encompassing the biggest chunks of the world made available to scientists for visual inspection, not least where humans could not be present, as in deep space, and telescopically reaching out to many million light-years, even billions. ${ }^{3}$ But in the end human perception has to come into it, and it does not seem possible to forestall the "fallacy of immaculate perception" (Sellars, 1968), no matter how automated the processes of image capture and storage may be, human knowers are not perfect perceivers, even if attaining a high degree of veridical perception, no doubt explained by natural selection, directly or indirectly (so much we can concede to evolutionary epistemology), and representations of any kind are necessarily bound up with

3 Machine sounds also became salient in the soundscapes of cities from the late nineteenth century and the Italian Futurists of the early twentieth century never ceased to proclaim their defining role in urban-industrial societies. In science, despite the advances in sonification, detected sounds are, in general, translated into audiographs, digital read-outs and visual images for the purposes of research. 
conventions of one sort or another, more or less theoretically grounded, even if informally or tacitly.

There is also the path of endowing ourselves with digital electronic super-senses, so that our vision could switch from our normal mode to a telescopic or microscopic mode, and back again, and our other senses could be similarly "augmented", if not so easily. Whether acquiring an electronic digital super-sensorium coupled to our stillorganic body, possibly connected to an electronic super-motorium (via an exoskeleton, for example) is something of interest for the pursuit of science is questionable, though we would become super-percipients, or at least super-visualizers. Yet another way of significantly amplifying the seen world for everyone would be if the "perfect lens", or "superlens", is manufactured, as seems possible theoretically with metamaterials, and a miniature ultra-high resolution microscope becomes as common as cameras in smartphones and other mobile devices: such a microscope would enable us to see a virus in a drop of blood, for example. "Deep seeing" of the micro-world would be democratized, we would all feel closer to the nanoworld, citizen science (which continues to play an important role in, for example, observational astronomy, as well as in taxonomic tasks in and out of astronomy) further enabled another extension of the humanly visualizable world. (One is irresistibly reminded of Swift's Lilliputians). On a more modest scale, the embedding of perfected 3-D imaging devices in mobile phones would significantly enhance visualization of the outer world for everyone. However, such extensions would still be bound to Euclidean visual space, a cultural artifact of modernity, rather than the recovery or re-inclusion of hyperbolic visual space together with Euclidean space "within an enlarged realism [which] would make a positive statement about the primacy of perception, and the centrality to perception of physical embodiment in the (material fabric) of the universe" (Heelan, 1983, p. 278).

The project of universal observation and recording, or "mapping" of everything visible at the highest degrees of resolution or magnification continues to appeal. In any case, the classes of visibilia, the classes of things, or aspects of things, that can be made visible or detected, or even measured, for visibilia can be mensuranda, through electronic technology, increase daily. 4 This was also coupled with the potentialities of photographic representation, envisaging a "total" continuous photographic record in at least fragments of natural history or in specific areas of human behavior, a project which has recurred in connection with computational devices, electronic sensors, probes, observational geosynchronous satellites, and so on, as they emerged in the second half of the twentieth century. In the pursuit of science, as well as in all kinds of 
other endeavors, anything and everything has become a potential object of photography, still or cinematic, regardless of moral reservations or religious interdictions. However, few research fields in the natural sciences relying on photography or film acquired special labels, like "cine-biology", whereas in every science today the prefixes "computational", "cyber", "digital", or "e-" are pervasive, and conjoined to the names of every science.

The role of images in the sciences entered a new phase when easily available digital electronic computers with their ever-increasing processing power began to develop substantial graphic and pictorial capabilites in the 1970s, though other key innovations, like computer simulations, had been pioneered in the 195 os. ${ }^{5}$ These capabilities have grown exponentially as processing power and storage capacity of computers increase, doubling every two years, as they have done since the 1960 s, according to Moore's law and Kryder's law respectively, with a concomitant halving in costs to the consumer. The advent of the PC made available to scientists vastly more computer time than previously, when the scarcity of computer time was a key constraint in scientific research, and, concurrently, far more processing power than the most powerful computer classes, with the exception of the Cray supercomputers. In each decade the average new computers enjoy the processing power that supercomputers alone had in the previous decade. Instead of just number crunching, computers, or computational devices, came to play roles in scientific research which had not been anticipated (in fact, scientists looked for what they could do with the new computing resources rather than having a clear-cut pre-established agenda of how to exploit them), so far-reaching in its wealth of cognitive affordances, ${ }^{\mathbf{6}}$ that scientists now speak of computational science as a "third methodology of science" or a "third form of science", the "computational mode", alongside the theoretical/mathematical and the experimental modes of older vintage (cf. Kaufmann \& Smarr, 1993, p. 4). Unlike the others, it views reality itself in terms of discrete units, so it was, at least potentially, or in an "as if" (als ob) mode, as much an ontological as a methodological revolution, at any rate a shift in a preferred meta-scientific "theme". It has certainly lent support to a metaphysics of discreta rather than continua, 7 even the claim, now widely shared amongst physicists, that (digital) information should be construed as equiprimordial with matter

5 Monte Carlo simulation originated in the modeling work for the hydrogen bomb, via the efforts of the mathematicians Ulam and von Neumann. Born in sin, one might say, even if two geniuses presided over its birth.

6 Using the term "affordance" in a sense akin to that of Gibson in the psychology of perception: the ensemble of the possible operations one can perform (including the perceptual aspects of an object that can be elicited thereby) with a device, especially those undesigned and unforeseen.

${ }_{7}$ Of course, it is acknowledged that some kinds of atomic particles violate Leibniz' law of the identity of indiscernibles, that there cannot be numerical difference without qualitative difference. 
and energy, a "categorial revolution", that is, involving not only conceptual change but, more far-reachingly, the introduction of a new, fundamental category of thought. The recent technological achievement of the single atom silicon transistor shows how close matter and information can be brought. In any case, the science of computation itself has claimed a status in the system of the sciences on a par with that of the physical or life-sciences, and indeed in some ways overlapping with them, for leading physicists and biologists argue for the existence of natural computational processes in the physical and biological worlds (cf. Rosenbloom, 2013).

Computers assist mathematicians with proofs of theorems (the four-colour map theorem was finally proved in 1976, the first computer-assisted mathematical proof ever), mapping topologies, transforming numerical data as they became available in ever larger sets, in the empirical disciplines, astronomy/astrophysics and in a lot of others, most strikingly perhaps for the lay public in neuroscience, into visual representations, not least digital images, regarded as "photographs" by most laypersons, endowed with "false colour" for ease of viewing. 8 The computational mode of doing science, of "sciencing", could also be described as "visualization science", as it routinely converts numerical data into images in the "dry laboratories" and the automated observatories (where torrents of images may arrive daily). It is characteristic of its thrust that in every scientific field today publications so often refer to "maps" and "mapping", from "mapping" the galaxies, and indeed all that can be captured by our instruments of the cosmos (cf. Osserman, 1995), to "mapping the brain" via imaging technologies (even "whole-brain mapping" may be routine), as in the Allen Brain Atlas, "mapping DNA", or mapping human haplotypes (the genetic differences in our species) or the HapMap, or "mapping the mind" (cf. Carter, 1998), the Inner Geographies Project, and even to mathematical "maps" on the computer screen, making the sciences appear as so many variants of "cartography", in a broad sense of the term, the terms "atlas", "albums" or "charters" being also very recurrent in a lot of scientific fields (cf. Hall, 1992). Such characterizations suggest a "geographical exploration model" of scientific inquiry, which would point to a completability in principle of the scientific world picture, and thus the end of scientific revolutions in due course (cf. Rescher, 1978): not what "mapping" enthusiasts have in mind, perhaps. Long ago Stephen Toulmin (1961) compared scientific theories to maps, in part also with the aim of discounting Kuhnian-type scientific revolutions avant la lettre: not surprisingly, he later backed the development of evolutionary epistemology against Kuhn.

8 Scientists call such pictures, and all pictures meant for display, rather than analysis, "pretty pictures" (they may be endowed with other aesthetic attributes besides colour). Digital processing technologies have made their production much easier, of course. 
The coming of computers with advanced graphic capabilities fostered the development of chaos theory in the 1970s, a fertile theoretical approach in the physical sciences, and the closely related complexity theory. Digital computers were not the key to the emergence of chaos theory (which may be defined as the study of unpredictable behavior in simple, bounded, deterministic systems). From about 1975 digital computers enabling graphical displays became widely available and this made possible further developments. Mathematical formulations of nonlinear dynamics which existed since Henri Poincaré wrote the first ones in 1892, were revived and developed in the 1960s. Experimental evidence had been elicited repeatedly, but disregarded, "bracketed" or subjected to "institutionalized neglect", owing to the regnant "clockwork universe" of classical physics (though some physicists and philosophers in the second half of the nineteenth century argued that even within the framework of deterministic classical physics, unpredictability could arise). The resources of analogic computers would have been sufficient for graphic displays, even if not as compellingly demonstrative as those of the digital computers of the 1970s (cf. Kellert, 1993, p. 119-48).

In turn, chaos theory lent itself to further production of images not only of didactic value but also, incidentally, with remarkable aesthetic properties as books like The beauty of fractals showed. 9 "While philosophical accounts [of science] typically cast the item to be explained as a linguistic entity, researchers in chaos theory more often will point to a computer graphics display and say, "this is what we need to understand" (Kellert, 1993, p. 81, nota, my italics). The explanandum for these researchers would not be an observation-statement, or even an e-reading (a numerical digital readout), but what one may call an e-graphic, a graph generated by a digital computer. Digital images can, of course, be stored, easily retrieved, shared, compared, replicated perfectly (though in a sense there are no originals), transmitted instantly to any number of scientists anywhere, through computer-assisted communications (CMCs), including communications satellites.

In practically every field of scientific inquiry, data abundance or data glut has replaced the classical condition of chronic data scarcity or arduous data acquisition (this circumstance may have a selective effect on those who stay the course after early graduate work in the natural sciences): big data is by no means confined to what used to be called "big science". Special auxiliary subfields emerged devoted to fast - and

9 Further on this see chapter ${ }_{5}$, entitled "Beautiful chaos", of Kellert (2008). Mathematicians speak of the beauty of proofs, physicists of the beauty of equations, and sometimes even of beautiful experiments. Artists don't generally speak of beauty anymore, but find varied aesthetic affordances in the scientific images of the day. Some are even ecstatic about the "beauty" of the LHC, that super-machine, though perhaps a category mistake is involved, and what they feel falls under the category of the sublime rather than of the beautiful, specifically an instance of the "technological sublime" (cf. Marx, 1964; Nye, 1994), or the "technoscientific sublime” (cf. Hoffman \& Whyte, 2011). 
ever faster - processing of huge data sets, such as bioinformatics, chemoinformatics and neuroinformatics: indeed workers in these subfields have become full-time specialists, creating a further division of labor in the sciences, between data-gatherers and data-analysts (scientists strive for something like Moore's law in the information growth of their own fields, and indeed genomic sequencing can now boast of having surpassed Moore's law). Ever more powerful scopic instruments have come along: besides optical and radar telescopes, there are also radio, X-ray, infra-red and ultra-violet telescopes, electronic and scanning probe microscopes, and the first atomic X-ray laser was invented recently, opening a new window into the world of molecules and atoms. They enabled visualization with unprecedented degrees of accuracy and resolution in the cosmos and the microcosm (the digital microscope provides the image in the monitor directly, bypassing the human eye).

Computer simulation is now routine in all the natural sciences; even in mathematics, such "numerical experiments" have come to be accepted, though still questioned by some (mathematics has become in part an experimental science, in this sense, rather than that of physical experiments), ${ }^{10}$ and "virtual experiments", as they are sometimes called (cf. Rees, 2004), ${ }^{11}$ in other fields are conducted in "dry" laboratories (science in silico), especially where actual physical experiments would be physically impossible in the "wet" laboratory (science in vitro), or otherwise barred, or if they pertain to the inaccessible past or to future possibilia. They also take place as a daily practice as a guide to the choice or design of the most appropriate physical, "real" experiments. Computer simulation enables the exploration of counterfactual universes (even if within the range allowed by the laws of physics), the creation of "would-beworlds" and the observation of their evolution, for the range of "free variation" of hypothetical states-of-affairs that can be processed to construct alternative scenarios, to imagine alternative realities, is immense, compared with what would have been feasible only a few years ago, with graphic displays, digital images or plotting points on screen maps, to assist reasoning, or, as chaos theorists often put it, "to create intuition". Likewise, thought-experiments in science and philosophy too have been characterized, in-

10 The new contrast between theoretical and experimental mathematics cuts across the old dichotomy between pure and applied mathematics.

11 They used to be called "theoretical experiments" or "mathematical experiments". Of course, thought-experiments, unaided by computers or any other external device, could also be called "theoretical experiments", carried out in the "laboratory of the mind" (cf. Brown, 1993), and in recent years there has been much interest in the role of gedankenexperimente, especially in the history of twentieth century physics between 1905 and the 1930 . Even as late as the 1970s, some physicists questioned whether simulations should be called experiments, being done on keyboards rather than on laboratory benches. The consensus view now is that the boundaries between computation and physical experimentation ("bench experimentation") have become blurred, paralleling the blurring of boundaries between the cyber and the physical, the virtual and the real, taking place across the whole of the civilization of digital images. 
dependently, as "intuition pumps" (cf. Dennett, 1991). The extensive use of computer simulations in climate science, and above all the predictions of major climate change, and the anthropogenic role in it, based on them, have triggered much scepticism or denial. Some of it is based on reasoned methodological argument, or empirical evidence, but most is ideological or political. The research programs of artificial intelligence and artificial life, in their weak or strong versions, must of course proceed through computer simulations. ${ }^{12}$ Virtual experiments enable a certain kind of "virtual reality" to be addressed. The term "virtual reality" came into circulation after its adoption by the computer scientist and musician Jaron Lanier. It was derived from the terminology of the philosopher Susanne Langer, who, in her writings on aesthetics, formulated the concepts of "virtual space" for painting, "virtual time" for music, and "virtual power" for the dance decades previously (cf. Langer, 1953). Virtual reality may encompass time, space, power, afford synaesthetic experiences and even proprioceptive ones.

In his monumental survey of the "material culture" of microphysics in the twentieth century, Peter Galison (1997) distinguished therein three subcultures, the experimentalist, the instrumentalist, and the theoretical, each with a degree of relative autonomy and distinct histories which do not neatly coincide in their periodization, but intercalate (each with a certain degree of immanent change, one might say). More to the point, he contrasted two epistemic traditions throughout the history of twentieth century microphysics, cutting across all three subcultures, but particularly impinging on "traditions of instrument-making" and "ideals of experimentation": the "image" tradition, and the "logic" tradition (it is somewhat extravagant to refer to them, as the author does, as the traditions of iconodules and iconoclasts). In the image tradition, the emphasis is on visual representation, mimetic or "homomorphic", the goal being "the production of images of such clarity that a single picture can serve as evidence for a new entity or effect" (Galison, 1997, p. 19), a tradition culminating in the bubble chamber. In the logic tradition, "counting (rather than picturing) machines aggregate masses of data to make statistical arguments for the existence of a particle or effect" (p. 19). To be sure, even followers of the image tradition had to analyse statistical evidence! The two traditions, the mimetic and the aniconic, came to coalesce from the 1970 onwards, with the rise of electronic imagery, as experimental devices became information machines. The story can be told in terms of the epochs of data, for

12 This can lead to a "trained incapacity" for wonder. The much publicized original photo of the blue planet taken by astronauts was perhaps the most "iconic" of technoscientific photographs of the last six decades. Yet its impressiveness was somewhat lost on the Apollo astronauts themselves, who had become all too familiar with the matching simulations during their training prior to the voyages. Dwelling too long in virtual reality can bring about "holomelancholia". After the much-quoted Weberian disenchantment of the (real) world, the disenchantment of the virtual one. 
"in the late twentieth century the typical form of data in microphysics became "the controlled image': in many domains beyond particle physics, one sees the binding of picturing with counts" (Galison, 1997, p. 809, my italics). An example: "radio astronomers grafted their electronic deductions to visual astronomy with charged coupled detectors and computers" (p. 809-10). In a nutshell, "the controllable image came to supplant the century-old ideal of objectivity that the chemical photograph had embodied. Knowing through the passive registration of the eye no longer stood apart from knowing through manipulation" (p. 810). Apart from astronomy, of course, as we can manipulate so very little in the heavens through "experimental astronomy", working with miniaturized models is a large part of the scientific enterprise. Scientists can create and manipulate digital worlds at will, whatever the parameter space, the more so, the more the processing power and speed of computers increase, as has been happening for the last fiftyodd years, and will go on happening for the next few decades at least.

Perhaps the scientific domain where imaging technologies, based on microelectronics and nuclear science, have had the most impact on the general public, apart perhaps from cosmology, or impinged most directly on vital human interests, has been that of cognitive neuroscience in the last few decades. ${ }^{\mathbf{3}}$ The great advances in brain imaging, with a succession of imaging technologies coming into play, whose acronyms have become familiar (EEG, PETA, MRI), but it is the "functional" versions, such as fMRI, which enable the researcher to view processes unfolding, not merely static anatomy. It is functional neuroimaging which has been claimed as the major research instrument in this field, certainly the one which has most impressed the public. The diffusion of such images in magazines, pop science writing, educational videos and films, and the like, have helped to lend credibility to the extravagant pronouncements made with great fanfare by a number of neuroscientists, not so much about specific brain science issues, but about perennial metaphysical and theological issues, on the ontological status of the mind, the relation of the mind to the body, the issue of libertarian free will, the nature of the self or the human person. In addition, the same ones, or others, have published best-sellers, become media gurus, advertise therapy programs, personality change, self-help, cognitive enhancement, and so on, supposedly on the basis of neuroscience and the allure of its imagery (cf. Thornton, 2011). Some neuroscientists have become neuroeconomists, or even neuromarketing entrepreneurs, to promote ways in which brands might attract more customers, by selecting the commercial messages most likely to activate the appropriate regions of the brain,

13 From time to time, imaging technologies can precipitate moral and political strife, in part because of their unanticipated use, as in the case of fetal ultrasound images. The replacement of the stethoscope by ultrasound devices in medicine may also bring strains in the doctor-patient relationship. 
as identified by neuro imaging studies. A kind of neurocentric perspective has emerged in which social, cultural, political, economic phenomena are all related in the first instance to the wiring or rewiring of the brain (cf. Tallis, 2011), something conducive to "neuroessentialism".

The question of the evidential status of images, of their weight in scientific argumentation is raised acutely in this field, and much intra-disciplinary disputation has taken place on this matter. In any case, the alleged grounding of the far-reaching metaphysical theses advanced by neuroscientists on the latest imagery made availa-ble by powerful new imaging tools is questionable, as very similar theses were advanced a century ago, by brain scientists who propagandized them with equal certitude and fanfare.

\section{ON THE EPISTEMIC IMPLICATIONS OF IMAGERY IN THE HARD SGIENGES}

We seem to have moved full circle from the Victorian era when visual models were practically mandatory in physics, through the era when visualizability was deemed as unavailable for the micro-world, understandable in quantum-physical terms only via abstract, non-intuitable, models, and an aniconic mode prevailed in the philosophy of science ("picture-thinking" was definitely downgraded by practically every school of thought, banning imaginative projection of the molar into the molecular world), ${ }^{\mathbf{1 4}}$ to the present-day milieu when scientific research in the hard sciences, as well as scientific publication and communication within science and of science to nonscientists, is awash with visual images. It was claimed a couple of decades ago that visual imagery would no longer have the importance it had enjoyed in the late twentieth century (cf. Brunet, 2000): in fact, it has never been so important in the sciences as a whole. To be sure, images, photographs, always need to be interpreted, according to prevalent methodological canons, to be credited epistemically, but the point is that they are not subsidiary or irrelevant to argumentation proper. This increased saliency of the image in science (of machine images, digital visual images, prevalently), in the mainstream, and not in the margins of scientific endeavour, stems in great measure from the muchvaunted contemporary "Data Revolution", the growing massive "cyberinfrastructure" of science ("e-science") - this is the term promulgated by the US National Academy of Sciences -, with the multiplication, accelerated potentiation and miniaturization of

14 Cf. this fairly typical statement by a nuclear physicist: "electrons and photons are too small to be seen and must therefore not be endowed with visual properties (...). The biblical injunction 'Thou shalt not make thyself a graven image' needs to be taken just as seriously by today's science as it was by the early Israelites" (Margenau, 1987, p. 46). The converse surely does not follow, for we can see atoms, yet we are barred by extant theory from attributing visual properties to them. 
computational devices of all kinds, sensors and digital cameras as well as ever more powerful scopic, robotized, instruments with capacities for accessing, scanning, visualizing the megaloscopic as well as the microscopic worlds (now the nanoscopic world too) many orders of magnitude greater than earlier versions. ${ }^{\mathbf{1 5}}$

Imaging, specifically in the mode of electronic digital visual imaging, reaches into every phase of scientific inquiry, observational, experimental, simulational (or virtual-experimental), modeling, even in mathematical research ("experimental mathematics", where the experiments are also virtual, or "mathematical mapping"). Of course, mathematical tools (and mathematically formulated scientific laws or algorithms), in the broad sense of the "mathematical sciences" (logic, probability and statistics, and mathematics proper) are absolutely essential in all these phases, either embedded in computational devices or in the analysis of computer-generated data: there may be a kind of nonvicious circularity in that computer programs interrogate computer-generated data ("analytics", business or other). Computers, of course, work on numerical or imagetic/graphic/diagrammatic/mapping/audio/video or word modes. Computer-assisted proofs in mathematics, such as that of the four-colour theorem, are still relatively infrequent, although it is not clear why this should be the case (Russian mathematicians called it "machine mathematics"): at least one mathematician, who had published papers referring to his computer collaborator in theorem-proving by a human pseudonym, ascribing this to "human-centric bigotry".

This unprecedented combination of mathematical tools and machine-generated images, especially digital visual images, which have proliferated in enormous quantities and exhibit every kind of resolution and magnification, even into the nanoscale (it is a cliché to say that computers, initially dealing mainly in numbers and words, currently deal mainly with pictures), partly defines contemporary science. Some have called it "cyberscience", the third paradigm of sciencing, others have gone beyond this to herald the fourth paradigm of science, highly data-intensive, massively computerindebted science. Some claim that a "new kind of science" has come into being (cf. Wolfram, 2002), postulating a computational model of the universe-as-program. With computer-like "rules" instead of the "laws" of nature, in the conventional understanding of science, and the "book of nature" becomes, as it were, a cosmic "e-book" (but

15 The Earth system itself could become something like its own sensorium. This would come about as a result of the multiplication of electronic nano-sensors which can be installed everywhere, diffused throughout as "smart dust", and the mapping by satellites, which can see into the ocean floor and into the interior of the Earth, and infer something of geo-history (remote sensing via the LANSATs, for example). In a more mundane fashion, the expansion of the "Internet of things" and RFID systems connecting mobile devices, and sensor-endowed entities of all kinds, natural and cultural, inorganic or organic (e.g., the barcoding of as many bio-species as possible), via our intermediation and remote sensing would assist in the process. 
full of 3-D pictures in colour). ${ }^{\mathbf{1 6}}$ On Darwinian principles, which appeal to scientists in every discipline, a few simple rules can generate inexhaustible novelty. Wolfram is by no means alone in positing the cosmos to be a computer simulation, or at least entertaining this novel metaphysical "world-hypothesis".

Another way of characterizing the current state of the hard sciences, would be as one of mathematical imagism, or, better, algorithmic imagism, since not all algorithms need be mathematical (in any case, some mathematicians and scientists now claim that algorithms have superseded free-standing equations, or should). Ours is certainly a world shaped by both algorithms and machine images in our electronic screen-saturated lives in and out of laboratories. In any case, numerical models or observational findings tend to be visualized, "mapped" ("mapmaking" is now the business of every science, and even mathematics), or "charted", for ease of understanding, to stimulate discovery, to improve pattern-recognition, through digital images (cf. Hall, 1992).

Mechanical models enjoyed preeminence in the late Victorian period, when physicists like Kelvin claimed that they could not understand a physical process if they could not visualize a mechanical model for it, thereby incurring the celebrated severe strictures of Duhem (1906). This was followed by the anti-imagistic phase of mathematical idealism, mathématisme or logical empiricism. Neurath, the greatest propagandist of the movement, and the most politically engaged, developed a system of pictoral representation, the "Isotypes", on which he rested great hopes for both public enlightenment and scientific communication. Yet none of the monographs in the International Encyclopaedia of Unified Science, which he founded, including Kuhn's The structure of scientific revolutions, contained a single picture. This surely would not be repeated in a comparable enterprise today. Now imagism, or, more broadly, data-ism, has acquired full citizenship in science (and is struggling for a similar status in the humanities and to a lesser degree in the social sciences) ${ }^{\mathbf{1}} \mathbf{6}$ in the age of ubiquitous, ever-expanding, world-encompassing electronic imagery. The regulative ideal of the "legibility of the world" (Blumenberg, 1986) has been partially replaced by or at least complemented with that of the imageability of the world, which can be effected thanks to the wondrous and continuing sucesses of imaging technologies in our time. There was a current of thought, often called "mathematical idealism" (we formulated the concept of "mathematical imagism" in contrast with this position), in which precisely the de-

16 Actually, all the pictures in Wolfram's book (there are a thousand of them) are in black and white, but surely this could be "enhanced".

17 A diverting example was the "Phillips machine" at LSE, built in 1949 by the engineer-economist A. W. Phillips. This creaky hydraulic machine, replicas of which were still in use in 2009, provided a visual model of Keynesian macro-economics and was indeed admiringly viewed by leading economists, though it missed the essence of keynesian dynamics, which hinges on expectations and uncertainty, nor did it address the problem of inflation. 
mand for pictorial representations in scientific cognition, certainly in exact science, in mathematical-experimental physics, was regarded as radically inappropriate. Two academic philosophers who had formulated this position well before the quantum revolution of the 1920s, Ernst Cassirer in Germany, and Léon Brunschvicg in France, wrote extensively on the history and philosophy of physical science and mathematics. According to this perspective, the advance of mathematization in theory-construction, idealization, the transcending of all kinds of imagery or visual models in scientific cognition, the emancipation from every vestige of anthropomorphism, was the path of scientific progress: the primacy of intelligibilia over sensibilia in science had to be constantly reasserted.

Even if we must recognize that not everything of interest to science can be imaged, advances in this respect take place all the time, down to the atomic level and to a few hundred million years after the big bang, but not beyond. And the fact that we can obtain images of the remote cosmic past, the "retroverse", shows that the telescopes in question operate also as palaeoscopes, so to speak, and can do nothing else, given relativistic space-time. ${ }^{\mathbf{1 8}}$ It is in cosmogony that the palaeoscopic function of science is perhaps most effective in the whole range of what Whewell called the "palaeoetiological sciences".

Some scientists and mathematicians, as well as science writers in such magazines as Wired, have been carried away by the data/image/virtualization explosion in scientific research to the point of saying, perhaps not entirely as boutades, that the age of theory in the sciences is over with the instauration of big data and electronic imagery (numerical data can be translated into pixels) arising from the new mode of production of scientific data. Since data means potentially information, and even knowledge, one might even call it the new mode of production of scientific knowledge, beyond "mode 2" (cf. Gibbons et al., 1994), "mode 2.1", but that would have to include the new social relations (or, better, socio-technical relations) of knowledge production, collaboration in situ and beyond, via computer-mediated communications (CMC), in the shape of the emerging "networked science". ${ }^{19}$ It is alleged to be over, not so much because of any impasse in theory construction in microphysics or cosmology, or the experimental barrenness of the dominant grand theory in physics (though such claims have been made from within the physics community itself, admittedly by a minority),

18 The term "chronoscope" has been suggested, but I believe my term "paleoscope" is more fitting.

19 The systems theorist Russell Ackoff (1989) constructed the fourfold hierarchy data-information-knowledgewisdom, which has become fashionable in business management literature. With data at the base, information has to be extracted from data, and certified knowledge from information, which seems plausible. Wisdom, the highestlevel achievement, is another matter, being non-algorithmic by definition, and always, unlike the other three components, in short supply at all times, not least when we most need it. 
or because the experimentalists, or what one might call the "observationalists" (especially the cosmic mappers in their epic undertakings) have finally won the battle for supremacy against the theorists (but with "virtual experimentation", i.e., computer simulations, now added to physical or laboratory bench experimentation, practically as co-equal if not more, at least in terms of time allotted and the intensiveness of such work). Rather, it is argued that, with the immense sets of immense data sets now available and growing space, accompanied by exponential increases in computing speed and data-handling capability via close collaborative work, not necessarily in situ, ${ }^{20}$ with increasing pressures for online data sharing and for fast publication online in the scientific community theory-work cannot and need not proceed as hitherto. With the coming of the age of "networked science", which, however, according to its chief prophet, may take decades to realize its full potential (cf. Nielsen, 2012), in considerable part data-driven (images and non-images), and of "networked facts" (cf. Weinberger, 2012), science may not need sustained theorizing, or at least not the pursuit of High Theory, any more, as a distinct and separate epistemic enterprise, with a commanding role in the growth of scientific knowledge, ${ }^{\mathbf{2 1}}$ as happened in the twentieth century, heralded perhaps by the 1905 publication of the special, or "physical", theory of relativity, if not that of the general theory of relativity. The network metaphor has been around a long time in the philosophy of science, in one way or another. Those who take it seriously may be sympathetic to a coherentist theory of thruth, which need not be, though often has been, associated with a rationalist epistemology and an idealistic metaphysics. Versions of coherentism, a holistic empiricism, were embraced by Neurath and later by Quine. In both cases their scientific holism stemmed in part from recognition of the force of Duhem's theses on how scientific tests in physics can never be simply that of a single hypothesis, law-statement or theory in isolation, for it is always a comprehensive body of knowledge which is at stake in such situations, implicitly at least (cf. Duhem, 1906).

20 The collectivization of scientific research is evident in the multiple-authorship phenomenon, with dozens and dozens and even sometimes a couple of hundred signatories of short scientific research articles: one of its sources was experimental nuclear physics, thus a by-product of big science, with its huge machines and decades-long experiments, but it has spread far beyond that area, and even beyond laboratory science proper. Indeed, in 2011 a response to an article questioning inclusive fitness theory in evolutionary biology, published in Nature, was signed by 137 biologists! Public authorities and funding agencies promote collectivization of scientific research with financial and other incentives. Yet reward systems, such as the Nobel Prizes in the sciences, serve only for the recognition of individuals, not of teams, not even recognizing the collaboration of more than three individuals (though via the ranking of universities within and between countries, a collective recognition effect ensues).

21 But see a recent statement by a physicist: "Theoretical physics (...) is a kind of science distinct and somewhat different from physics. When physicists work on a theory, they are not dealing directly with nature, but with an abstract model in which they have already decided which aspects of reality must be absolutely retained, and which ones can be dismissed" (Vignale,2011, p. 3, italics in the original). 
It is suggested that the huge, ever-expanding and multiplying data bases (numbers, words, images, graphs, tables, etc., and sound), comprising volumes measured in terabytes and petabytes, which can be merged as well shared via the internet, can only be analyzed pari passu, so to speak, on Bayesian paths. And indeed Bayesian inference has become the commanding type of inference in much scientific or science-based work in all empirical domains statistical regressions, or neural networks, deployed in every phase of market-economic activity. Bayesianism, it has been claimed, owes its revival and indeed its current dominance to the computer revolution and the big data explosion of recent years, still going on (cf. Hand, 2007). ${ }^{22}$

Bayesian inductivism is today a major position, possibly the major position, in the philosophy of science, or rather the methodology of science; its neo-Baconian resonances would justify calling its current program as something like that of a novum organum redivivus. To be sure, there are, of course, other anti-deductivist positions amongst those who endorse the "semantic view of [scientific] theories", according to which theories should be regarded as families of models, in one fashion or another, such as Rom Harré, Bas van Fraassen, Ronald Giere, who in other ways stand for very different epistemological positions, "referential realism", "constructive empiricism", "perspectival realism", respectively (not to mention John Worrall's "structural realism"). All the works on the data-drivenness of empirical inquiry stress predictive successes, usually relatively short-run, list innumerable examples, and point to the predictive power still to come from big data, issuing from our own ever more frequent digital acts or from other instrumental sources, owing to algorithms and programs capable of analyzing in ultra-fast fashion many thousands of attributes of scientific or medical objects at once, unsurveyable by humans (predicting crime just before it happens, predicting illnesses before symptoms manifest themselves in the case of "selftrackers", neuroscientists turned neuromarketers predicting shopping behaviour, medical scientists predicting how long anyone can live, predictions of song hits or film blockbusters etc.). But explanatory power, or more specifically, explanatory depth, is rarely stipulated as a prime desideratum, though for Popperians (cf. Watkins, 1984), and some other philosophers of science, such as Rescher (1978), the growth of science involves a kind of ladder of theories with ever-increasing explanatory range and depth. Similarly Toulmin long ago stressed that explanation, rather than prediction, is the prime goal of science proper, as distinct from applied science. Toulmin (1961), though for a time, under the covering law model, the paradigm-case of scientific knowledge

22 A comprehensive discussion of Bayesianism can be found in a summa by one of its leading exponents, Salmon $(2005)$. A sophisticated discussion of the philosophical issues around the much-publicized antagonism between the Bayesian outlook and Popper can be found in a paper by Gelman \& Shalizi (2013). 
entailed a logical symmetry between explanation and prediction). Toulmin considered Babylonian astronomy the paradigm case of predictivist science. Feyerabendian philosophers of science later attempted to vindicate the legitimacy of this style of science, as against the Greek theoretical tradition. Today some strands of science, with their strong emphasis on algorithms for predictive purposes (predictive analytics), or algorithms instead of theories or equations, exemplify another semi-Babylonian phase of science (only "semi" because that work takes place against the background of a corpus of well-established theories). Or we could call it "positivist", like Stephen Hawking: "I (...) am a positivist who believes that physical theories are just mathematical models we construct, and that it is meaningless to ask if they correspond to reality, just whether they predict observations" (Hawking, 1997, p. 169).

This is not to say that Bayesianism is necessarily incompatible under some construals with some key exigencies of Popperian methodology, though some of its exponents in the philosophy of science have seen it as completely superseding the Popperian vision of the aims of science (cf. Howson \& Urbach, 1989). Crudely put, one could say that in data-intensive science (which is also visualization-intensive: a good deal of today's datasphere, in the sciences as elsewhere, could be called an imagesphere or videosphere), algorithms are referred to far more often than laws, models invoked far more than theories, the success of predictions far more often than the power of explanations, utility rather than systematicity or architectonics. These shifts in epistemological emphases go together with the changes in the moral economy of science, the emergence of "post-academic science", in the characterization by the physicist John Ziman (the PLACE model), such as the rise of proprietary knowledge-production (cf. Ziman, 2004). Thus, besides these substantial changes in the scientific ethos, we should take into account a re-orientation in the logos of science, in epistemology and methodology, as we noted, and also in ontology, with the shift to a digitalist or discontinuist outlook, to computational and informational models of all domains of inquiry, the propensity to regard statistical phenomena as the underlying reality, what has been called "stochasticism" (cf. Galison, 1997, p. 738 ff.), often associated with the ergodic axiom. ${ }^{23}$ These ideational currents, if contested, may be gaining ascendancy.

23 The "ergodic axiom" is, put very simply, the assumption that the observed phenomena, or large data sets already available for statistical analysis, provide a fair sample of the domain under scrutiny (Davidson, 1991; 2007). This would rule out Taleb's "black swans" or Mandelbrot's "wild randomness" ("second-order indeterminism"), but, as we have seen in recent years, events, catastrophic or near-catastrophic ones, which were not supposed to happen in millions and millions of years, according to standard financial economics, did happen. As pointed out by many critics of mainstream economics, this axiom rules out uncertainty as a distinct epistemic or ontological modality, subsuming it under risk (cf. Martins, 2012, ch. 5). Economists and engineers often characterize as "irrational" the lay public's fear of catastrophic events with extremely low probabilities, such as meltdowns in nuclear power sta- 
In any case, it is argued that in the era of cyberscience, science is not longer so much "theory-driven", as in the twentieth century, in physics and chemistry in particular, a circumstance reflected and apotheosized in some currents of the philosophy of science, not least in Popper and dissident Popperians like Lakatos or Watkins, as "tool-driven". The "tools" comprise not just hand tools, or the inexpensive table-top devices that were sufficient for the Rutherford era of atomic physics, but the ever "smarter" miniaturized equivalents of much bigger, more powerful high-energy machines, or laboratory instruments, but also instances of big science, large technological systems, the LHC of CERN being the ultimate exemplar of the genus. We could also say that it is computer-driven, with ever-more powerful instrumentalities for observation, imaging and measurement of the microscopic/nanoscopic and megaloscopic worlds, and indeed the computer is today the tool for making cognitive tools par excellence. Inasmuch as it is tool-driven/computer-driven, instead of theory-driven, it is also data-driven, with the explosion of data-sets and the now normal orders of magnitude of petabytes in data volumes, and soon with even higher orders of magnitude. ${ }^{24}$ Some scientists now speak of an emerging "fourth paradigm" of science: after the theoretical ("analytical"), the experimental (empirical), and the simulation methods paradigms, that of data-driven science or data-intensive scientific discovery (cf. Hey; Tamsley \& Toll, 2009). In this age data reign (data include images or are susceptible to visualization through computerized graphics, so "imagification" goes hand in hand with quantification), and algorithms rule. The processing of the data deluge via computation, the universal instrument of science today, is key. Some proclaim the end of theory, and even those who would not go this far stress phenomenological modelling and predictive power rather than theory development in the context of the "fourth paradigm" of science (cf. Martins, 2012, ch. 3).

Concurrently, and not just coincidentally, tool-driven science is also team-work driven or "collaboratorial". Insofar as it is tool-driven, if the outer frontier of technological possibility in "excavating" nature were reached, or, more likely, if funding for ever larger/more powerful telescopes, terrestrial or in outer space, or huge high-energy particle accelerators and the like, were no longer available, basic science would

tions, but there is wisdom in that fear: indeed the Great Recession was deemed an event of extremely low probability by financial economists (including the recipient of the Nobel Prize in economics in 2013), as was an event of potentially disastrous consequences for the world financial system, the collapse of a major financial firm.

24 The "digital humanities" or "humanities 3.o" field are characterized by the same data-drivenness of the field, collectivization (multiple authorship and team-work the new normal), on-line sharing, an emphasis on the role of images in research, and a similar downgrading of theory, quite understandable in this case in the light of the high theory phase of postmodernism and deconstructionism, when literary theory assumed an egregious, paradoxical superiority vis-à-vis literature itself. 
more or less come to a stop (cf. Rescher, 1978; 1984). Some physicists, like Steven Weinberg (1974), have warned repeatedly that cuts in funding for such machines will end "the search for the laws of nature".

In his late treatise on logic as the theory of inquiry, Dewey (1938) argued for the criterion of "warranted assertibility" for propositional science, though of course he stressed the experimental and instrumental phases of scientific inquiry (we don't need to endorse the pragmatist theory of truth to share this emphasis). Sixty-odd years later, at a time when electronic imagery pervades science, this exigency should be supplemented by that of what we might call, by analogy with the Deweyan formulation, warranted imageability, for the admissibility, pertinence, reliability, validity, the evidential weight and argumentative bearings of images in science are matters that demand continual scrutiny (there are cases of evidentially spurious images in matters of considerable import in biology and even in physics). Thus in science "trust in numbers" has to be accompanied by "trust in images" (an issue in modern science since the invention of Galileo's telescope in 1609), given appropriate quality control mechanisms. The "principle of permanent control" (cf. Kaufmann, 1944, p. $5^{3}$ ff.) surely applies here as well as in the propositional or numerical corpus of scientific tenets, theorems, theories and models, as the potential falsifiability, corrigibility or revisability of their import and scope of validity of any such must be ensured, according to fallibilism, even if the falsifiability criterion has been recently attacked by eminent physicists. ${ }^{25}$ Doubtless, "networked science", an expanded, hyper-connected, globalized, telematic version of Fleck's "thought collectives" (cf. Fleck, 1979), or, more concretely, scientists-in-networks, must agree on the epistemic warrants of one may call networked images. These are mostly digital visual images or graphical displays of one sort or another, "e-graphics" (as I have called them), by analogy with "networked facts", which may be conveyed also in non-imagetic fashion (in general, keyed to "e-readings" or digital readouts). ${ }^{26}$ Data in the sciences today, even in the field sciences, tend to be mostly capta, obtained by technological devices increasingly coupled to ICTs (even the petri dish), with the advance of the automation of some phases of science (especially observational science) and of science in silico.

25 In the case of mathematics, "weak fallibility" along the lines of a Lakatosian philosophy of mathematics. Paraconsistent mathematics is a recent development, though paraconsistent logics have been around for several decades (Newton da Costa being a key exponent), latterly in the form of "dialetheism" (Graham Priest).

26 In an influential work, the astrophysicist A. S. Eddington asserted that "pointer-readings" were the mark of exact science (cf. Eddington, 1928). Today, pointer-readings have been largely replaced by digital read-outs. Hence I have suggested the term "e-readings" as the twentieth-one century counterpart of the twentieth century pointerreadings in the exact sciences (they are also ubiquitous in medicine and many other fields). 
Automation of science work has gone further with the development of "robot scientists". The "robot scientist" was introduced a few years ago in an article written by a team of British geneticists in Nature, welcomed by an editorial in the same issue of the journal. It consisted of a computer software program that could review the literature on a pre-given problem, formulate a hypothesis and test it on the data base supplied: if rejected, it would pursue a new hypothesis, and so on. The first version simply confirmed existing knowledge, but a later version made a discovery, with findings not previously available in the literature (all the researches were in the molecular biology of yeast). Further development by the same team may lead to improved knowledge discovery by software programs. The usual classification of laboratories into "wet" and "dry" will need to be supplemented by a third category, what we might call the ultra dry laboratory, with no humans in attendance.

In terms of a possible neuroscience of science, or, perhaps one should say, of a neurophilosophy of science, it might be asked, finally, what difference to the scientific enterprise the novel features of permanent search, capture and assessment of digital images in every phase of the scientific life may make. Especially as human scientists, professional or "citizen scientists" (as distinct from robot scientists), are in every other phase of their lives immersed in digital images also (though smart robots could, and almost certainly will, also be afforded immersion in the digital imaginarum via the "Internet of things"). This epistemic culture seems likely to prevail, with ever more extensive, continuous and multimodal interactions between humans and computers, or between humans and creatures of artificial intelligence, androids, smart robots and the like, though humans may be endowed with "smart" brain-implanted devices conjoined to electronic digital super-senses, ${ }^{27}$ between human scientists and robot scientists, if not a "fusion", "melding", "merger" or "symbiosis" between humans and AI devices, ${ }^{28}$ between wetware (fleshware, meatware) and software. This techno-human condition has often been proclaimed as inevitable, imminent, and eminently desirable since the 1960s, by a number of computer scientists. They seem to be very fond of

27. Locke (1970 [1700]) noted that humans lack microscopic eyes to see the ultimate particles. With prosthetic microscopic eyes, the major electronic digital super-sense under development, we will be able to see, not the ultimate particles, but certainly deep into the world of matter.

28 Oddly, the terms "hybrid" and "hybridization", so ubiquitous today, have not been much used in this context, though the term "chimera" is familiar in biomedical commentary. I have not assumed any kind of principle of symmetry, or parity, ontological, methodological or epistemological, between human and non-human (robotic, computational or other) contributors, agents or actants, natural or machine intelligence, in the processes of scientific investigation in or out of the laboratory. And I have not ruled out the concept of collective agency (with humans as co-agents), even if it has to manifest itself with and through technological means and media. "Collective epistemology" surely does not entail symmetry amongst knowers, or epistemic agents, of varied kinds. 
the rather tricky biological metaphor of "symbiosis", which they tend to literalize, in a somewhat eschatological mode, though some of them would settle for another, that of "co-evolution" of humans in general, and scientists in particular, and technology, which need not entail symbiosis in the strict sense. We might even plausibly envisage the coming of new epistemic cultures, arising out of the circumstance that scientists work as consumers and producers of images in and out of laboratories (wet, dry or ultradry), observatories, and other networked scientific research sites, in close association with numerical models, in a quite unprecedented fashion (prevalently "post-photographic" digital images, yielded by image technologies (cf. Ihde, 1993) and scanning devices of ever greater electronic, photonic, nanotech or quantum tech sophistication). Much the same could be said of "knowledge-workers" in general, the variously named "cybertariat", "digital proletariat", “cognitariat", "digerati”, "artificial intelligentsia”, "virtual intelligentsia", as a whole. This new form of scientific life may in due course have a significant impact on our pre-existing cognitive abilities, perceptual or conceptual, even induce a rewiring of the brain, with lasting effect, in particular thought collectives, or even on the Great Society of WWW-linked "networked science" (though the brain is not any kind of digital computer, digital computers or, eventually, quantum computers, may change the brain to suit themselves, as it were, through various selection effects, natural or cultural). Consider the "Flynn effect", the steady rise in average IQ of national populations observed in a number of industrialized countries, including Japan, over several decades from the mid-twentieth century until quite recently. The most substantial gains in IQ scores were in visual-spatial intelligence, as we might expect from continual exposure of generations to electronic media, and latterly to video games on a vast scale.

Similar questions might be asked a fortiori concerning non-scientific life in the current stage of the civilization of (electronic digital) images, in which all media (the computer today can itself be regarded as a medium, indeed increasingly as the medium of media, via smart phones or other mobile devices, wearable or ubiquitous computing) are digitized, in which the majority eventually will be made up of digital natives, and in which the pressures to virtualize scientific as well as other activities, cognitive and non-cognitive, seem irresistible. There has been much speculationsome guidance can be gleaned from comparisons with previous revolutions in ICTs (cf. Logan, 2004) - as to the difference ubiquitous and time-intensive Internet usage by such a large proportion of Western populations, with practically everyone immersed in the digital imaginarium of our times, or the addiction to videogames, may make to our cognitive dispositions and powers, such as the outsourcing of memory, reliance on external storage systems, biassing the economy of attention, a propensity to "digital 
distraction". ${ }^{29}$ As far as virtual reality is concerned, a portion of the digital demos is already attuned to the virtual rather than to the real, or at least to augmented reality, $3 \circ$ deeming it, in effect, ontically and axiologically privileged (cf. Heim, 1993). There is likely to be an increased call for avatars to stand in for us in the most varied situations and activities, blurring ever more the boundaries between the virtual and the real: perhaps an "X-reality" is emerging through the interweaving of the proceedings of real persons and their virtual clones (cf. Coleman, 2011), or an infinite virtual reality deprivileging the real real (cf. Blascovich \& Bailerson, 2011). In the civilization of digital images, of ever-multiplying online tools or apps, the outsourcing to virtual or artificial reality of practices of all kinds, scientific or other, in one fashion or another, is likely to proceed unrelentingly: indeed, triumphalists speak of a "rising tide of cognitive outsourcing" (which will include an ever-expanding "Internet of things"). Accordingly, an increasing amount of science work, including scientific discovery, would be done for us, not by us, by advanced "robot scientists", surrogate epistemic agents, which will be getting smarter and smarter, even if the prospect of AGI (Artificial General Intelligence) still seems distant, even with the capacity for "deep learning" now accruing to intelligent devices. Some of it is taking place far beyond our planet, via our space probes and missions, outsourced, like everything else today, though even more so, space-time-wise. One wonders how far co-attribution to these artificial epistemic agents of their knowledge production shared with humans will proceed (thinking of the mathematician I mentioned earlier, who co-signed his proofs with an imaginary human-sounding name for his computer, whose assistance, in his view, was crucial). I suppose this is an issue that pertains as much to artificial ethics as to artificial epistemology: will they ever become full members of the "scientific community"?

But whether the scenarios of the attenuation, if not the obliteration, of the boundaries between the digital and the physical such as those between computation and bench experimentation, the virtual and the real, natural and artificial (algorithmic) intelligence, via the spread of mind/brain-machine interfaces, or between organic matter and information, as enunciated by synthetic biology, which claims the potential ability to read and edit the genomic information of all living organisms, will

29 Complaints by educators and cultural critics about the hindrances to or even the loss of the capacity for sustained attention go back to the late nineteenth century, traced to the analog media of the time and metropolitan civilization, its visual culture and soundscapes, marketing practices, entertainment industries, and work life. The concept of the "economy of attention" is perhaps more recent, like the expression "digital distraction" (cf. Gordon \& Bogen, 2009). 3o Google is marketing augmented reality spectacles. Augmented reality will therefore be easily available to everyone via one wearable device, not just to citizen scientists. As mentioned before, a number of microelectronic devices have been designed which could make everyone a super-percipient in visual terms. Scientists are also working on other digital electronic prosthetic super-senses (including a nano-ear). 
be realized, is another matter. Along the same lines, investors have been advised that with three-dimensional printing becoming ever-cheaper and fantastically versatile, there will be no longer any important difference between a computerized artifact designed in "the cloud" and a real, physical thing. This may well be the next stage of "image capitalism”, or indeed of manufacturing capitalism, if all goes well. Time will tell.ه

Acknowledgement. The original version of this text was written at the request of Professor Olga Pombo of the University of Lisbon. I thank Bridget Fowler, João Bettencourt da Câmara and Martin Jay for helpful comments on an earlier version of this paper (my apologies to anyone I may have forgotten in this connexion).

\section{Hermínio Martins}

St. Antony's College, University of Oxford, United Kingdom.

Institute of Social Sciences, University of Lisbon, Portugal. herminio.martins@virgin.net

\section{REFERENGES}

Ackoff, R. L. From data to wisdom. Journal of Applied Systems Analysis, 16, p. 3-9, 1989.

Blascovich, J. \& Bailerson, J. Infinite reality: avatars, eternal life, new worlds and the virtual revolution. New York: Harper Collin, 2011.

Blumenberg, H. Die Lesbarkeit der Welt. Frankfurt: Suhrkamp Verlag, 1986.

Brown, J. R. The laboratory of the mind: thought experiments in the natural sciences. London: Routledge, 1993.

Brunet, F. La naissance de l'idée de photographie. Paris: PUF, 2000.

CAPEK, M. The philosophical impact of contemporary physics. Princeton: Van Nostrand, 1961.

Carter, R. Mapping the mind. London: Weidenfeld/Nicolson, 1998.

Coleman, B. Hello avatar: rise of the networked generation. Cambridge: The MIT Press, 2011.

DAvidson, P. Is probability theory relevant for uncertainty? A Keynesian perspective. Journal of Economic Perspectives, 5, 1, p. 129-43, 1991.

. John Maynard Keynes. Basingstoke: Palgrave Macmillan, 2007.

Dennetr, D. C. Consciousness explained. Boston: Little, Brown \& Co., 1991.

Dewey, J. Logic: the theory of inquiry. New York: Henry Holt, 1938.

Dunem, P. La théorie physique: son objet, sa structure. Paris: Chevalier/Rivière, 1906.

Eddington, A. The nature of the physical world. Cambridge: Cambridge University Press, 1928.

Engell, J. \& Bate, W. J. (Ed.). Coleridge biographia literaria. London: Routledge, 1983 [1817].

FLECK. L. The genesis and development of a scientific fact. Chicago: University of Chicago Press, 1979 [1936].

Galison, P. Image and logic: a material culture of microphysics. Chicago: University of Chicago Press, 1997.

Gelman, A. \& Shalizi, C. R. Philosophy and the practice of Bayesian statistics. British Journal of Mathematical and Statistical Psychology, 66, p. 8-38, 2013. 
Gibbons. M. et al. The new production of knowledge: the dynamics of science and research in contemporary societies. London: Sage, 1994 .

Gordon, E. \& Bogen, D. Designing choreographies for the "new economy of attention". Digital Humanities Quarterly, 3, 2, online, 2009. Available at: <http://www.digitalhumanities.org/dhq/vol/3/2/000049/ ००००4. html $>$. Accessed: 20 Oct. 2013.

Gusdorf, G. Réflexions sur la civilisation de l'image. In: Gusdorf, G. et al., Civilisation de l'image, Paris: Fayard, 1960. p. 11-36.

Gusdorf, G. et al. Civilisation de l'image. Paris: Fayard, 1960.

HALL, S. S. Mapping the next millennium: how computer-driven cartography is revolutionizing the face of science. New York: Vintage, 1992.

HAND, D. J. Information generation: how data rule our world. Oxford: Oneworld, 2007.

Hankins, T. L. \& Silverman, R. J. Instruments and the imagination. Princeton: Princeton University Press, 1995 .

Hawking. S. The objections of an unashamed reductionist. In: Penrose, R. (Ed.). The large, the small, and the human mind. Cambridge: Cambridge University Press, 1997. p. 169-72.

Heelan, P. Space-perception and the philosophy of science. Berkeley: University of California Press, 1983.

Негм, M. Electric language: a philosophical study of word processing. New Haven: Yale University Press, 1986. The metaphysics of virtual reality. New York: Oxford University Press, 1993.

Hey, T.; TAnsley, S. \& Told, K. (Ed.). The fourth paradigm: data-intensive scientific discovery. Redmond: Microsoft Research, 2009.

Hoffman, R. \& Whyte, I. B. (Ed.). Beyond the finite: the sublime in art and science. Oxford: Oxford University Press, 2011.

Howson, C. \& Urbach, P. Scientific reasoning: the Bayesian approach. La Salle: Open Court, 1989.

Iнde, D. Postphenomenology: essays in the postmodern context. Evanston: Northwestern University Press, 1993.

Ivins Junion, W. M. Prints and visual communication. London: Routledge and Kegan Paul, $195^{3}$.

JAY, M. Downcast eyes: the denigration of vision in twentieth century French thought. Berkeley: University of California Press, 1993a.

Force fields: between intellectual history and cultural critique. New York: Routledge, 1993b.

Jonas, H. The phenomenon of life: toward a philosophical biology. New York: Harper \& Row, 1966. . The nobility of sight: a study in the phenomenology of the senses. In: toward a philosophical biology. New York: Harper \& Row, 1966a. p 135-56. The phenomenon of life:

Kaufmann, F. Methodology of the social sciences. New York: Oxford University Press, 1944.

Kaufmann, W. J. \& Smarr, L. L. Supercomputing and the transformation of science. New York: Scientific American Library, 1993.

KELLERT, S. H. In the wake of chaos: unpredictable order in dynamical systems. Chicago: University of Chicago Press, 1993.

Borrowed knowledge: chaos theory and the challenge of learning across disciplines. Chicago: University of Chicago Press, 2008.

LANGER, S. K. Feeling and form: a theory of art developed from philosophy in a new key. London: Routledge and Kegan Paul, $195^{3}$.

Lanier, J. You are not a gadget. London: Penguin, 2011.

Locke, J.An essay concerning human understanding. Cambridge: Cambridge University Press, 1970 [1700].

Logan, R. K. The sixth language: learning a living in the internet age. Toronto: Stoddart, 2004.

Magfarlane, A. \& Martin, G. The glass bathyscaphe. London: Profile, 2003.

Margenau, H. The miracle of existence. Boston: New Science Library, 1987. 
Martins, H. Experimentum humanum: civilização tecnológica e condição humana. Belo Horizonte: Fino Traço, 2012.

Marx, L. The machine in the garden:technology and the pastoral ideal in America. New York: Oxford University Press, 1964 .

Miller, A. I. Imagery in scientific thought: creating twentieth century physics. Cambridge: The MIT Press, 1984 .

MitcheLl, W. The reconfigured eye: visual truth in the post-photographic era. Cambridge: The MIT Press, 1992.

Nersessian, N. J. Creating scientific concepts. Cambridge: The MIT Press, 2008.

Nielsen, M. Reinventing discovery: the new era of networked science. Princeton: Princeton University Press, 2012.

Novitz, D. Pictures and their use in communication: a philosophical essay. The Hague: Nijhoff, 1977.

NyE, D. American technological sublime. Cambridge: The MIT Press, 1994.

Osserman, R. Poetry of the universe: a mathematical exploration of the cosmos. New York: Anchor, 1995 .

Penrose, R. (Ed.). The large, the small, and the human mind. Cambridge: Cambridge University Press, 1997 .

Polanyi, M. Personal knowledge: towards a post-critical philosophy. London: Routledge \& Kegan Paul, 1958.

REEs, M. Our final century: will the human race survive the twenty-first century? London: Arrow, 2004.

Rescher, N. Scientific progress: a philosophical essay on the economics of scientific research. Pittsburgh: Blackwell/University of Pittsburgh Press, $197^{8}$.

. The limits of science. Berkeley: University of California Press, 1984 .

Rosenbloom, P. On computing: the fourth great scientific domain. Cambridge: The MIT Press, 2013.

Salmon, W. Reality and rationality. Oxford: Oxford University Press, 2005.

Schivelbusch, W. The railway journey: the industrialization of time and space in the nineteenth century. Oxford: Blackwell, 1979 .

SelLars, W. Science and metaphysics. London: Routledge \& Kegan Paul, 1968.

Sicard, M. La fabrique du regard: images de science et appareils de vision, XVe-XXe siècle. Paris: Odile Jacob, 1998.

TALLIS, R.Aping mankind: neuromania, Darwinitis and the misrepresentation of humanity. Durham: Acumen, 2011.

Thовnтоn, D. J. Brain culture: neuroscience and popular media. New Brunswick: Rutgers University Press, 2011.

Toulmin, S. Foresight and understanding: an enquiry into the aims of science. London: Hutchinson, 1961.

VIGnaLe, G. The beautiful invisible: creativity, imagination, and theoretical physics. Oxford: Oxford University Press, 2011.

Watkins, J. Science and scepticism. Princeton: Princeton University Press, 1984.

Weinberg, S. Reflections of a working scientist. Daedalus, 103, 3, p. 33-45, 1974.

WeINBerger, D. Too big to know: rethinking knowledge now that the facts aren't the facts, experts are everywhere, and the smartest person in the room is the room. New York: Basic Books, 2012.

Wolfram, S. A new kind of science. Champaign: Wolfram Media, 2002.

Ziman, J. Real science. What it is, and what it means. Cambridge: Cambridge University Press, 2004.

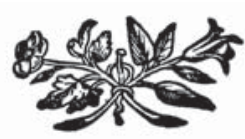

